Canadian Journal of Family and Youth, 8(1), 2016, pp 19-45

ISSN 1718-9748 ( ) University of Alberta

http://ejournals.library.ualberta.ca/index/php/cjfy

\title{
Apples to Apples: A Comparative Demographic Analysis of Homeless and Housed Youth in Canada
}

\author{
Kristy Buccieri, Laura Warner, Ross Norman, Mo Jeng, Amanda Wright and Cheryl Forchuk
}

\begin{abstract}
The demographic profiles of homeless youth are varied and play an integral role in the experiences these young people have. This article reports on detailed demographic data collected from 187 homeless youth in the Youth Matters in London study, and compares it to demographic profiles of youth in the general Ontario population and with samples of homeless youth from five major Canadian cities. Results indicate demographic data is not consistently collected and/or reported upon by researchers, making comparative analysis challenging while highlighting the need for a standardization of demographic data collection. Comparisons between homeless and housed youth indicate that the homeless youth had lower educational attainment, higher pregnancy/parenting rates, increased cohabitation, greater unemployment, and low annual incomes. Demographic comparison between the six homeless youth samples indicate some similarities and some key differences, particularly in relation to pregnancies/parenting, education, employment, and income. Implications for researchers, policy-makers, and service providers are discussed.
\end{abstract}

Kristy Buccieri, Ph.D., is an Assistant Professor in the Department of Sociology at Trent University. Her research examines Canadian experiences of homelessness, with particular emphasis on health, youth, and spatial dimensions. Recent publications include: 1) Buccieri, K. \& Molleson, G. (2015). Empowering homeless youth: Building capacity through the development of mobile technology. Journal of Community Practice, 23(2), 238-254; 2) Gaetz, S., O’Grady, B., Buccieri, K., Karabanow, J., \& Marsolais, A. (Eds.). (2013). Youth homelessness in Canada: Implications for policy and practice. Toronto, ON: The Canadian Homelessness Research Network. Electronic copy available online: http://www.homelesshub.ca/Library/View.aspx?id=55618. Laura Warner, MSc, is an epidemiologist working in the field of mental health. Current research interests include social inclusion of psychiatric survivors and homelessness amongst both adults and youth. Recent publications include: 1) Meier, A., Csiernik, R., Warner, L. \& Forchuk, C. (in press). The Stigma Scale: A Canadian perspective. Social Work Research; and 2) Hall, P., Montgomery, P., Davie, S., Dickins, K., Forchuk, C., Jeng, M., Kersey, M., Meier, A., Lahey, P., Rudnick, A., Solomon, M. \& Warner, L. (in press). Seeking and securing work: Individual-level predictors of employment outcomes of psychiatric survivors. Work. Ross Norman, Ph.D., is a Professor in the Department of Psychiatry at Western University. His research focuses on the effects of stress on psychiatric illness, particularly psychosis and the evaluation of innovative approaches to treatment and service delivery in psychiatry. Recent publications include: 1) Windell, D. L., Norman, R., Lal, S., \& Malla, A. (2014). Subjective experiences of illness recovery in individuals treated for first-episode psychosis. Social Psychiatry and Psychiatric Epidemiology; and 2) Norman, R. M. G., Carr, J., \& Manchanda, R. (2015). Cognition and the prediction of functioning in patients with a first treated episode of psychosis: A prospective study. Schizophrenia Research, 162, 138-142. Mo Jeng, Ph.D., is the Manager of Social Research and Planning within the Department of Community Services for the City of London. His research interests include homelessness and mental health. Recent publications include: Forchuk, C., 


\section{Buccieri et al.}

Godin, M., Hoch, J. S., Kingston-MacClure, S., Jeng, M. S., Puddy, L., Vann, R., \& Jensen, E. (2013). Preventing psychiatric discharge to homelessness. Canadian Journal of Community Mental Health, 32(3), 17-28. Amanda Wright is a Research Coordinator at the Lawson Health Research Institute. Her research interests include youth homelessness and mental health supports. Cheryl Forchuk, Ph.D. is a Distinguished University Professor and Associate Director of Nursing Research at the Arthur Labatt Family School of Nursing (Western University) with a cross appointment to the Department of Psychiatry, Schulich School of Medicine and Dentistry (Western University). She is also a Scientist and Assistant Director for the Lawson Health Research Institute. Currently, her research explores systems issues related to mental health care including implementation of the transitional discharge model, housing/homelessness issues, poverty, community integration and the use of technology in mental health. Recent publications include: 1) Forchuk, C., Richardson, J., Laverty, K., Bryant, M., Rudnick, A., Csiernik, R., Edwards, B., Fisman, S., Mitchell, B., Connoy, M., Dolson, M. S. \& Kelly, C. (2013) Service preferences of homeless youth with mental illness: Housing first, treatment first, or both together. In S. Gaetz, B. O'Grady, K. Buccieri, J. Karabanow, \& A. Marsolais (Eds.), Youth Homelessness in Canada: Implications for Policy and Practice. (pp. 95-110). Toronto, ON: Canadian Homelessness Research Network Press; and 2) Forchuk, C., Csiernik, R. \& Jensen, E. (2011) "Homelessness, Housing And The Experiences Of Mental Health ConsumerSurvivors: Finding Truths Creating Change.” Toronto, Ontario: Canadian Scholars Press. 
Apples to Apples

\section{Introduction}

Effective planning for any population requires a sound understanding of the characteristics that define its members, and differentiate them from others. This article reports on the demographic characteristics of 187 homeless and street-involved youth enrolled in the Canadian-based Youth Matters in London (YML) study and compares the findings with demographic data collected from other large-scale studies of homeless youth in Canada, as well as with statistical data of youth who are housed.

Youth homelessness researchers often collect demographic information as part of their studies, with the recognition that they are working with a diverse population and that this information is needed in order to provide targeted interventions. Yet, while researchers collect demographic characteristics about their own sample participants - such as their age, sex, gender, sexual orientation, and race/ethnicity (among others) - this information is rarely used to conduct comparative analyses against other homeless youth samples and/or youth in the general population.

In this article we examine two key questions: (1) what are the demographic characteristics of the YML sample of homeless youth, and how do they compare to those of housed youth within the same Canadian province, of Ontario; and (2) how do the demographics of the YML sample compare to those of other homeless youth across Canada?

\section{Literature Review}

Demographic analysis is an integral part of social science and health-based research. According to the American Psychological Association (2001), describing the demographic profile of a sample can be beneficial for assessing the results, making comparisons between and 
Buccieri et al.

across groups, generalizing the findings, and making comparisons in replications, literature reviews, and secondary analyses. In recent years, collecting demographic information on homeless youth has become increasingly important, with the growing recognition that they are a heterogeneous population.

Studies are regularly conducted in Canada, the United States of America, and Australia, yet there has been limited concerted effort to examine the similarities and differences between the homeless youth samples included in the range of studies. Similarly, few researchers have attempted to undertake comparative analysis between homeless and housed youth samples. Some notable exceptions include matched-sample studies related to sexual minority youth (Walls, Hancock, \& Wisneski, 2007), psychopathology (McCaskill, Toro, \& Wolfe, 1998), family environment (Wolfe, Toro, \& McCaskill, 1999), and behavioural health problems (Haber \& Toro, 2009). Critical comparative analysis is imperative, especially given Toro, Lesperance, and Braciszewski’s (2011) caution that, “...studies find rather different profiles of homeless youth, depending on sampling strategies, target age groups, gender balance, measures used, and other methodological factors" (p.1).

To date there has been little uniformity in the kinds of demographic information collected and/or reported upon by youth homelessness researchers. This lack of consistency is concerning, given that recommendations put forth by researchers may be adopted into policy and practice, without critical evaluation of their generalizability to other locations and sub-groups of homeless youth. In 1998 the Public Health Agency of Canada (PHAC) launched a pilot project aimed at addressing the lack of consistency in data collection around this population of young people. The Enhanced Surveillance of Canadian Street Youth, generally referred to as E-SYS, was designed to collect data on street youth through multiple cycles and across various locations, such as 
Vancouver, Edmonton, Calgary, Saskatoon, Winnipeg, Toronto, Ottawa, and Halifax (PHAC, 2008). While this collaborative initiative has offered considerable insight into various street youth samples across Canada, the collection and evaluation of data remains an ongoing process. To date, only limited demographic information has been publicly reported as outlined in the results section of this article.

The need for consistent and comprehensive demographic reporting is rooted in the recognition that targeted responses offer the most promise for working with this marginalized group of youth. Living on the street presents these young people with many challenges, dangers, and risks, but not in a uniform way. Their experiences and responses are largely influenced by demographic factors, like age, sex, gender, sexual orientation, and race/ethnicity. In order to understand homeless youth, and offer strategic responses that benefit them, it is important to first understand the importance of these identity markers in shaping their experiences. Further complicating demographic analyses (yet making them even more pressing) is the intersectionality of these characteristics. For instance, while it is estimated that between $20-40 \%$ of homeless youth self-identify as lesbian, gay, bisexual, transgender, or questioning (LGBTQ) (Ray, 2006), the experiences of these youth are influenced not only by their sexuality but also by intersecting factors, such as Aboriginal identity (Abramovich, 2012).

Research has shown that demographic factors intersect in complex ways that go beyond simple notions of accumulating or multiplying disadvantage (Frederick, Ross, Bruno, \& Erickson, 2011). The implications of understanding demographics, and their intersections, are clear when examining the research on many issues effecting homeless youth today. For instance, while it is recognized that poor mental health is more common among homeless than housed youth (Thompson, Bender, Windsor, Cook, \& Williams, 2010; Votta \& Manion, 2004), detailed 
Buccieri et al.

demographic analysis indicates that certain conditions, like depression and dysthymia, are more commonly present in older and female homeless youth (Rohde, Noelle, Ochs, \& Seeley, 2001). Depression is also more common among LGBTQ identified youth (Frederick et al., 2011; Noell \& Ochs, 2001), with one study finding that in the preceding twelve months these youth were more likely than heterosexual youth to have seriously considered, planned, and attempted suicide (Gattis, 2013). A range of sex-based suicide indicators have also been identified among homeless youth, with male suicidality associated with being gay and having emotional distress, and female suicidality associated with being younger and having low self-esteem (Leslie, Stein, \& Rotheram-Borus, 2002).

The use of substances, commonly to self-medicate, is also higher among homeless youth (Kelly \& Caputo, 2007; Kirst \& Erickson, 2013; Sanders, Lankenau, Jackson-Bloom, \& Hathazi, 2008; Shillington, Bousman \& Clapp, 2011). Demographic factors play an important role in understanding different usage patterns (Baron, 1999). For instance, LGBTQ youth are more likely to report higher lifetime use (Gattis, 2013), a greater variety of drug use (Frederick et al., 2011), and injection drug use (Noell \& Ochs, 2001). Higher rates of substance use have also been found among homeless youth who are white/not Hispanic or African American and who are male (Salomonsen-Sautel et al., 2008).

The risk of becoming HIV-positive is reportedly higher among homeless youth (Boivin, Roy, Haley, \& Galbaud du Fort, 2005), and may be linked in part to high-risk substance use practices (DeMatteo et al., 1999; Marshall, Kerr, Livingstone, Montaner, \& Wood, 2008). Demographically, HIV-positive homeless youth are more likely to be older, male, of Aboriginal or African American descent, and low-income earners (Linton, Singh, Turbow, \& Legg, 2009). LGBTQ youth are also at high risk of acquiring HIV (Rew, Whittaker, Seehafer, \& Smith, 
2005); with research indicating bisexual females are at the greatest risk (Gangamma, Slesnick, Toviessi, \& Serovich, 2008). Positive HIV status may also be linked to high-risk behaviours like survival sex, which is more common among females (Gangamma et al., 2008) and LGBTQ youth (Gattis, 2013; Marshall, Shannon, Kerr, Zhang, \& Wood, 2010).

Delinquent behaviour often increases as young people enter street life (Thompson et al., 2010), but the relationship between homeless youth, criminality, and victimization is not straight-forward. While homeless youth, as a whole, report difficulty with the law (Coates \& McKenzie-Mohr, 2010; Votta \& Manion, 2004), there are clear demographic differences. Male youth are more likely to report receiving attention from the police (O’Grady, Gaetz, \& Buccieri, 2011) and being arrested (Kirst \& Erickson, 2013). African American and Aboriginal youth are also more likely to experience greater levels of police surveillance and harassment (O'Grady et al., 2011), while LGBTQ youth are less likely to report being arrested (Noell \& Ochs, 2001).

Victimization is common on the street as well. One in-depth study of homeless youth in Toronto found the most highly victimized to be young, female (particularly African Americans), and LGBTQ (particularly females) (Gaetz, O’Grady, \& Buccieri, 2010). Female youth often report altering their appearance to look tougher as a protective measure (Gaetz, 2004), however, other research has indicted that having an unkempt physical appearance may actually increase one's risk of sexual victimization (Tyler \& Beal, 2010). Male victimization may be associated with survival sex (Tyler, Whitbeck, Hoyt, \& Cauce, 2004), the use of a weapon (for those who are heterosexual) (Frederick et al., 2011), and is less likely to be reported to an authority figure (Gaetz, 2004).

Violence is not limited to the street, as many youth identify abuse as a reason for leaving home, particularly among young women (O’Grady \& Gaetz, 2004; Tyler et al., 2004). The home 
Buccieri et al.

lives of these youth are often described as problematic and, as such, many are involved with child welfare agencies and foster care (Coates \& McKenzie-Mohr, 2010; Nichols, 2013). This involvement is often particularly difficult for Aboriginal youth, given the historical trauma of residential schooling in Canada (Baker Collins, 2013; Ruttan, LaBoucane-Benson, \& Munro, 2008, 2010).

The demographic profiles of homeless youth are varied, and play an integral role in the experiences these young people have. The literature shows that demographic factors (such as age, sex, gender, sexual orientation, and race/ethnicity) impact their health, mental health, suicidality, substance use, HIV rates, engagement in survival sex, criminality, victimization, home lives, and involvement with child welfare authorities. Gaining a better understanding of the demographic characteristics of homeless youth is important, as it allows for a better understanding of who they are, how they experience complex issues, and how to best implement effective policies to assist them. A growing number of researchers are calling for targeted interventions that take into account the needs of youth, based on their demographic characteristics (Chisolm, Mulatu, \& Brown, 2009; Leslie et al., 2002; Rew et al., 2005). This article assists in this effort by providing detailed demographic data from the YML study, as well as a comparative analysis with other homeless and housed youth samples in Canada.

\section{Methods}

\section{Design}

The main objective of the YML project was to investigate and better understand youth participants' choices regarding treatment and service options over a three-year period. A crosssectional, mixed methods approach was used, with participants completing both an in-depth 
quantitative interview, as well as more qualitative open-ended questions. The quantitative component was based on several questionnaires, including such topics as demographics, health, housing, quality of life, and social support. Ethics approval was granted by the Research Ethics Board of Western University, in London, Ontario.

Sample

A total of 187 individuals were enrolled in the study, with all participants being initially located within the city of London, Ontario and its surrounding region. To be included in the study participants needed to be between the ages of 16 and 25 , experiencing a serious selfreported mental health disorder (a formal diagnosis was not required), and either homeless or precariously housed. Housing definitions followed those used by the At Home/Chez Soi study (Mental Health Commission of Canada, 2008). Individuals were considered to be absolutely homeless if they were living in places not usually used for sleeping (e.g. outside on the streets, in parks, cars, or parking garages); staying in shelters or hostels; or leaving an institution (such as a prison, jail, or hospital) with no place to stay. Individuals were considered to be precariously housed if they were staying in a Single Room Occupancy, rooming house, or hotel/motel, and had been absolutely homeless at least twice previously.

\section{Measures}

The current study is a secondary analysis based on three questionnaires from the YML study. These surveys included the 'Demographics, Service \& Housing History' (DSHH), 'Housing History Survey’ and ‘Vocational Time-line Follow-back' (VTF).

For each measure, with the exception of age, annual income, and the number of undesirable moves in the previous five years, individuals were given a list of categories and asked which category they belonged to. For example, to assess gender, individuals were asked to 
Buccieri et al.

indicate whether they were male, female, or other. For current sources of income, individuals were allowed to select more than one category. As for the measures that were not categorical in nature, age was determined by calculating the amount of time, in years, between the individual's reported date of birth and the interview date. Annual income was calculated from the VTF questionnaire where individuals were asked to estimate their total income from all sources for each of the previous three months. This was then summed for a three-month total, and multiplied by four to estimate the total annual income for the previous year. Finally, data regarding undesirable moves was taken from the Housing History Survey where participants were asked to estimate the number of undesirable moves they had experienced in the previous five years.

Where necessary, data from the YML sample was regrouped to match the CCHS categories, which allowed for a more direct comparison. Age was transformed into a categorical variable with four groups: 15 to 17 years; 18 to 19 years; 20 to 24 years; and 25 years. To be able to compare cultural/racial origins, data from YML was condensed from a long list of possible cultural identities (e.g. Asian-East, Asian-South, Black-Canada, Black-Africa, etc.) to two categories - White (i.e. White-Canada and White-Europe) and Visible Minority (i.e. all categories except for White-Canada and White-Europe). Education data originally contained categories which separated individuals attending a particular level from those who actually completed a level (e.g. completed grade 8; attended high school but did not complete; completed high school; attended university but did not complete; completed university). To be able to compare samples, individuals were regrouped into the following categories: less than secondary school graduation; secondary school graduation; some post-secondary; post-secondary graduation. With respect to current source of income, data was again condensed from a long list of options, (e.g. earnings from regular work, earnings from casual work, disability income, 
panhandling, etc.) to three categories: employment income; employment insurance, workers' compensation, and social assistance; and other. Finally, annual income was transformed from a continuous variable into a categorical variable with six groupings: no income; less than $\$ 20,000$; $\$ 20,000$ to $\$ 39,999 ; \$ 40,000$ to $\$ 59,999 ; \$ 60,000$ to $\$ 79,999$; and $\$ 80,000$ or higher.

Some data from the CCHS was also reclassified to achieve a more equal comparison. Number of children was derived from two questions: living arrangement; and number of individuals in the household. If the respondent did not indicate they were a parent living with a child they were considered as having 0 children. If they indicated they were either a) a parent living with a spouse/partner in a household of 3 persons; or b) a single parent living in a household of 2 persons they were considered as having 1 child. If they indicated they were a parent living with their partner/spouse in a household of 4 or more persons, or a single parent in a household of 3 or more persons they were considered as having 2 or more children.

Employment status was also based on two questions: working status last week and currently attending school, university, or college. Within the working status last week, if an individual indicated they had a job the previous week they were considered employed. If they indicated they did not have a job last week, or were permanently unable to work, they were considered unemployed. If an individual indicated they were currently attending school, university, or college, they were considered to be a student.

\section{Analysis}

The purpose of this paper is to compare the demographic characteristics of the YML sample with two key groups - housed Ontario youth and other homeless youth in Canada. First, the study sample was compared to a general Ontario youth sample. To that end, data was pulled 
Buccieri et al.

from two cycles of the Canadian Community Health Survey (CCHS) to serve as comparisons. The CCHS is a cross-sectional survey conducted by Statistics Canada that collects information related to health status, health care utilization, and health determinants for the Canadian population. Random digit dialing is employed within a pre-designed sampling frame in order to obtain reliable estimates for the Canadian population at the health region level.

Data from the 2009/2010 CCHS was chosen as one comparison, as data collection for this survey would have taken place around the same time as baseline data collection for the YML study. Data from the 2011/2012 CCHS was chosen as the second comparison as it reflects the most current data available on Ontario youth. Within the CCHS data, individuals who indicated they were between the ages of 15 and 24 years, and currently resided in Ontario $(n=5578)$ were selected for the comparison, and weights were applied as necessary for descriptive statistics.

For the categorical measures in both samples, frequencies and percentages were calculated. For the number of undesirable moves, the mean number of moves and the standard deviation were calculated.

As level of education can be highly dependent on age, and given the age groups in the two samples were not exact (i.e. YML included those 16 years to 25 years, and the $2010 \mathrm{CCHS}$ included those 15 years to 24 years) a sub-analysis of age group and education was undertaken. The percentage of individuals in each education level was calculated for each age group and compared between the YML sample and the 2010 CCHS sample.

The second objective, comparing the YML sample demographics with other homeless youth, was achieved by conducting a literature search through Google Scholar. Given that demographic data reporting may be limited in journal articles, the search was extended to include grey literature as well, through the review of on-line research reports. Five Canadian youth 
homelessness studies were identified that provided extensive reporting on demographic data.

These studies included three from the E-SYS project in Ottawa (Ottawa Public Health, 2011), Edmonton (Alberta Health Services, 2011), and Saskatoon (Public Health Services, 2011), as well as research conducted in Toronto (Linton et al., 2009), and Calgary (Worthington et al., 2008). Demographic data was collected, as reported by the researchers, and is presented alongside the YML data for comparative purposes.

\section{Results}

\section{Question 1: Comparing Homeless and Housed Youth}

The first question we explored was, "What are the demographic characteristics of the YML sample of homeless youth, and how do they compare to those of housed youth within the same Canadian province, of Ontario?" The comparison of sample demographics between the YML sample and housed Ontario youth can be found in Table 1. Overall, the CCHS cycles seem similar with little change between the earlier and later responses. There were, however, several notable differences between the YML sample and the two broader Ontario samples.

Table 1: Comparison of sample demographics to a broader Ontario youth sample

\begin{tabular}{|c|c|c|c|c|}
\hline & \multicolumn{2}{|c|}{ YML } & \multirow{2}{*}{$\begin{array}{c}\text { CCHS } \\
2009 / 10 \\
\%\end{array}$} & \multirow{2}{*}{$\begin{array}{c}\text { CCHS } \\
2011 / 12 \\
\%\end{array}$} \\
\hline & $\mathbf{n}$ & $\%$ & & \\
\hline \multicolumn{5}{|l|}{ Age (years) } \\
\hline 15 to 17 years $^{\mathrm{a}}$ & 27 & $14.8 \%$ & $29.7 \%$ & $29.4 \%$ \\
\hline 18 to 19 years & 39 & $21.3 \%$ & $19.0 \%$ & $17.3 \%$ \\
\hline 20 to 24 years & 113 & $61.7 \%$ & $51.2 \%$ & $53.4 \%$ \\
\hline 25 years & 3 & $2.2 \%$ & N.I. & N.I. \\
\hline \multicolumn{5}{|l|}{ Gender/Sex ${ }^{\mathrm{b}}$} \\
\hline Male & 122 & $65.2 \%$ & $51.7 \%$ & $51.0 \%$ \\
\hline Female & 62 & $33.2 \%$ & $48.3 \%$ & $49.0 \%$ \\
\hline Other & 3 & $1.6 \%$ & N.I. & N.I. \\
\hline \multicolumn{5}{|c|}{ Cultural/Racial Origins } \\
\hline White & 135 & $72.6 \%$ & $67.9 \%$ & $65.8 \%$ \\
\hline Visible minority & 51 & $27.4 \%$ & $32.1 \%$ & $34.2 \%$ \\
\hline
\end{tabular}




\begin{tabular}{|c|c|c|c|c|}
\hline & \multicolumn{2}{|c|}{ YML } & \multirow{2}{*}{$\begin{array}{c}\text { CCHS } \\
2009 / 10 \\
\%\end{array}$} & \multirow{2}{*}{$\begin{array}{c}\text { CCHS } \\
2011 / 12 \\
\%\end{array}$} \\
\hline & $\mathbf{n}$ & $\%$ & & \\
\hline \multicolumn{5}{|l|}{ Level of Education } \\
\hline Less than secondary school graduation & 149 & $79.7 \%$ & $34.6 \%$ & $33.0 \%$ \\
\hline Secondary school graduation & 27 & $14.4 \%$ & $20.6 \%$ & $22.9 \%$ \\
\hline Some post-secondary & 11 & $5.9 \%$ & $18.3 \%$ & $16.4 \%$ \\
\hline Post-secondary school graduation & 0 & $0.0 \%$ & $26.5 \%$ & $27.6 \%$ \\
\hline \multicolumn{5}{|l|}{ Marital Status } \\
\hline Single, never married & 146 & $78.9 \%$ & $90.7 \%$ & $93.5 \%$ \\
\hline Common-law/Cohabitating with partner & 37 & $20.0 \%$ & $5.0 \%$ & $6.2 \%$ \\
\hline Married & 1 & $0.5 \%$ & $4.0 \%$ & $2.4 \%$ \\
\hline Widowed, separated, or divorced & 1 & $0.5 \%$ & $0.3 \%$ & $0.3 \%$ \\
\hline \multicolumn{5}{|l|}{ Number of Children } \\
\hline 0 children & 131 & $70.8 \%$ & \multirow{3}{*}{ N.I. } & $97.3 \%$ \\
\hline 1 child & 39 & $21.1 \%$ & & $1.7 \%$ \\
\hline 2 or more children & 15 & $8.1 \%$ & & $0.9 \%$ \\
\hline \multicolumn{5}{|l|}{ Number of Children Provide Support To } \\
\hline 0 children & 22 & $40.7 \%$ & \multirow{3}{*}{ N.I. } & \multirow{3}{*}{ N.I. } \\
\hline 1 child & 28 & $51.9 \%$ & & \\
\hline 2 or more children & 4 & $7.4 \%$ & & \\
\hline \multicolumn{5}{|l|}{ Current Employment Status ${ }^{\mathrm{c}}$} \\
\hline Employed & 13 & $7.0 \%$ & $56.1 \%$ & $55.4 \%$ \\
\hline Unemployed & 140 & $75.3 \%$ & $43.9 \%$ & $44.6 \%$ \\
\hline Student & 31 & $16.7 \%$ & $63.2 \%$ & $66.3 \%$ \\
\hline Volunteer work, unpaid & 1 & $0.5 \%$ & N.I. & N.I. \\
\hline Other & 1 & $0.5 \%$ & N.I. & N.I. \\
\hline \multicolumn{5}{|l|}{ Current Sources of Income ${ }^{d}$} \\
\hline Employment income & 22 & $11.8 \%$ & $74.5 \%$ & $76.5 \%$ \\
\hline $\begin{array}{l}\text { Employment insurance, workers' compensation, } \\
\text { social assistance }\end{array}$ & 104 & $55.6 \%$ & $3.7 \%$ & $3.4 \%$ \\
\hline Other & 60 & $32.1 \%$ & $21.5 \%$ & $19.8 \%$ \\
\hline \multicolumn{5}{|l|}{ Total Annual Income ${ }^{\mathrm{e}}$} \\
\hline No income & 8 & $4.3 \%$ & $16.2 \%$ & $13.9 \%$ \\
\hline Less than $\$ 20,000$ & 158 & $84.9 \%$ & $57.8 \%$ & $60.4 \%$ \\
\hline$\$ 20,000$ to $\$ 39,999$ & 12 & $6.5 \%$ & $18.4 \%$ & $19.6 \%$ \\
\hline$\$ 40,000$ to $\$ 59,999$ & 4 & $2.2 \%$ & $5.9 \%$ & $4.7 \%$ \\
\hline$\$ 60,000$ to $\$ 79,999$ & 1 & $0.5 \%$ & $1.4 \%$ & $1.0 \%$ \\
\hline$\$ 80,000$ or higher & 3 & $1.6 \%$ & $0.2 \%$ & $0.5 \%$ \\
\hline
\end{tabular}

N.I. Not included in CCHS sample/questionnaire

a YML data reflects individuals with a stated age of 16 to 17 years

b YML asked participants for their gender where the CCHS asks for sex

c YML allowed for the selection of one primary employment status while the CCHS data allows for multiple statuses d YML allowed for the selection of multiple sources of income while the CCHS only allowed one

e YML annual income was calculated by taking the total income of the previous three months and multiplying by four 
From this analysis, the YML sample contains a slightly lower percentage of 15 to 17 year olds (14.8\% vs. $29.7 \%$ and $29.4 \%)$ yet a slightly higher percentage of 20 to 24 year olds (61.7\% vs. $51.2 \%$ and $53.4 \%$ ). This sample also includes a slightly higher percentage of males than what is found in the broader population $(65.2 \%$ vs. $51.7 \%$ and $51.0 \%)$. More than twice as many individuals in the YML sample had not yet achieved a secondary school graduation $(72.6 \%$ vs. $34.6 \%$ and $33.0 \%$ ) than in the CCHS samples. Comparison of marital status revealed individuals in the YML sample were three to four times more likely to be living common-law or cohabitating with a partner $(20.0 \%$ vs. $5.0 \%$ and $6.2 \%)$, but were far less likely to be married (0.5\% vs. $4.0 \%$ and $2.4 \%)$ when compared to the broader youth sample.

In relation to employment and income, direct comparisons are difficult due to the inherent differences in the questions used in the two samples. However, it does appear that individuals in the YML sample were far less likely to be employed (7.0\% vs. 56.1\% and 55.4\%) or to consider themselves a student (16.7\% vs. $63.2 \%$ and $66.3 \%)$, and far more likely to be unemployed ( $75.3 \%$ vs. $43.9 \%$ and $44.6 \%$ ) than their broader population counterparts. This is further highlighted in the current sources of income, where receiving employment income was six times more prevalent among the broader population (74.5\% and $76.5 \%$ vs. $11.8 \%)$, but receiving social assistance was 15 times more prevalent among the YML sample (55.6\% vs. $3.7 \%$ and $3.4 \%)$.

The analysis revealed key educational distinctions between the two samples. The results of the cross-tabulation between education status and age group are shown in Table 2 . In the 15 to 17 year age group the results are similar between the samples with $100 \%$ of participants in YML and $92.7 \%$ of the broader youth sample having less than a secondary school graduation. However, as the age increases there is a shift in the broader Ontario youth sample where the 
Buccieri et al.

prevalence of a less than secondary school graduation decreases (15 to 17 years: $92.7 \%$; 18 to 19 years: $22.8 \%$; 20 to 24 years: $6.9 \%$ ) while the prevalence of higher education levels, such as post-secondary graduation, increases (15 to 17 years: $0.1 \%$; 18 to 19 years: $7.2 \%$; 20 to 24 years: $51.4 \%$ ). The most drastic differences can be seen in the 20 to 24 year age group where the YML sample was ten-times more likely to have less than a secondary school graduation $(72.6 \%$ vs. $6.9 \%$ ), slightly less likely to have a secondary school graduation (18.6\% vs. $21.6 \%)$, less than half as likely to have some post-secondary education ( $8.8 \%$ vs. $20.0 \%)$, and far less likely to have a post-secondary graduation $(0.0 \%$ vs. $51.4 \%)$.

Table 2: Education status by age group comparing Youth Matters in London sample to a broader Ontario youth sample

\begin{tabular}{|c|c|c|c|c|c|c|c|c|}
\hline & \multicolumn{2}{|c|}{15 to 17 years } & \multicolumn{2}{|c|}{18 to 19 years } & \multicolumn{2}{|c|}{20 to 24 years } & \multicolumn{2}{|c|}{25 years +} \\
\hline & YML & $\begin{array}{c}\text { CCHS } \\
2010 \\
\end{array}$ & YML & $\begin{array}{c}\text { CCHS } \\
2010 \\
\end{array}$ & YML & $\begin{array}{c}\text { CCHS } \\
2010 \\
\end{array}$ & YML & $\begin{array}{c}\text { CCHS } \\
2010 \\
\end{array}$ \\
\hline $\begin{array}{l}\text { Less than } \\
\text { secondary school } \\
\text { graduation }\end{array}$ & $\begin{array}{c}27 \\
100.0 \%\end{array}$ & $\begin{array}{c}463352 \\
92.7 \%\end{array}$ & $\begin{array}{c}34 \\
87.2 \%\end{array}$ & $\begin{array}{l}74992 \\
22.8 \%\end{array}$ & $\begin{array}{c}82 \\
72.6 \%\end{array}$ & $\begin{array}{l}63480 \\
6.9 \%\end{array}$ & $\begin{array}{c}3 \\
75.0 \%\end{array}$ & \\
\hline $\begin{array}{l}\text { Secondary school } \\
\text { graduation }\end{array}$ & $\begin{array}{c}0 \\
0.0 \%\end{array}$ & $\begin{array}{l}13314 \\
2.7 \%\end{array}$ & $\begin{array}{c}5 \\
12.8 \%\end{array}$ & $\begin{array}{l}135366 \\
41.1 \%\end{array}$ & $\begin{array}{c}21 \\
18.6 \%\end{array}$ & $\begin{array}{l}197981 \\
21.6 \%\end{array}$ & $\begin{array}{c}0 \\
0.0 \%\end{array}$ & \\
\hline $\begin{array}{l}\text { Some post- } \\
\text { secondary }\end{array}$ & $\begin{array}{c}0 \\
0.0 \%\end{array}$ & $\begin{array}{l}22273 \\
4.5 \%\end{array}$ & $\begin{array}{c}0 \\
0.0 \%\end{array}$ & $\begin{array}{l}95363 \\
28.9 \%\end{array}$ & $\begin{array}{c}10 \\
8.8 \%\end{array}$ & $\begin{array}{l}183190 \\
20.0 \%\end{array}$ & $\begin{array}{c}1 \\
25.0 \%\end{array}$ & $\begin{array}{c}\text { Not } \\
\text { Included }\end{array}$ \\
\hline $\begin{array}{l}\text { Post-secondary } \\
\text { graduation }\end{array}$ & $\begin{array}{c}0 \\
0.0 \%\end{array}$ & $\begin{array}{c}707 \\
0.1 \%\end{array}$ & $\begin{array}{c}0 \\
0.0 \%\end{array}$ & $\begin{array}{l}23728 \\
7.2 \%\end{array}$ & $\begin{array}{c}0 \\
0.0 \%\end{array}$ & $\begin{array}{l}469915 \\
51.4 \%\end{array}$ & $\begin{array}{c}0 \\
0.0 \%\end{array}$ & \\
\hline Total & $\begin{array}{c}27 \\
100.0 \%\end{array}$ & $\begin{array}{l}499646 \\
100.0 \%\end{array}$ & $\begin{array}{c}39 \\
100.0 \%\end{array}$ & $\begin{array}{l}329449 \\
100.0 \%\end{array}$ & $\begin{array}{c}113 \\
100.0 \%\end{array}$ & $\begin{array}{l}914566 \\
100.0 \%\end{array}$ & $\begin{array}{c}4 \\
100.0 \%\end{array}$ & \\
\hline
\end{tabular}

\section{Question 2: Comparing Homeless Youth Samples}

The second analysis question asked, "How do the demographics of the YML sample compare to those of other homeless youth across Canada?" Table 3 provides comparative data on the YML sample demographics in relation to available information from studies with homeless youth in five major Canadian cities (from the three provinces of Ontario, Alberta, and 
Saskatchewan). These geographically diverse samples showed similar average ages (ranging between 19 and 24), were comprised primarily of males, and a majority in each city identified as white. London was the only city reporting marital status, with a notable percentage of youth living with a partner (20\%). The available information indicated a high rate of reported pregnancies and/or children in London (29.2\%), Ottawa (58\%), Edmonton (42.6\%), Saskatoon (61\%), and Calgary (42\%), although London and Calgary were the only cities to obtain this information from both males and females. Originally, we also set out to compare the number of children respondents were supporting, however, only London-based researchers collected this information.

Age-appropriate levels of education were attained by $46 \%$ of participants in Edmonton and by $25 \%$ of participants in Ottawa. The majority of participants had not completed high school in London (79.7\%), Toronto (50.7\%), and Calgary (67\%). Employment status information is considerably lacking, although sources of income data indicates employment is the most common source in Calgary (41\%), government assistance in London (55.6\%) and Ottawa (66\%), and other sources in Edmonton (45.1\%) and Toronto (39.6\%). Annual income showed the majority of participants in London reporting earning less than $\$ 20,000$ (84.9\%) and those in Toronto generally earning less than $\$ 15,000$ (71.0\%). 
Buccieri et al.

Table 3: Comparison of Youth Matters in London sample demographics to other Canadian homeless youth study samples

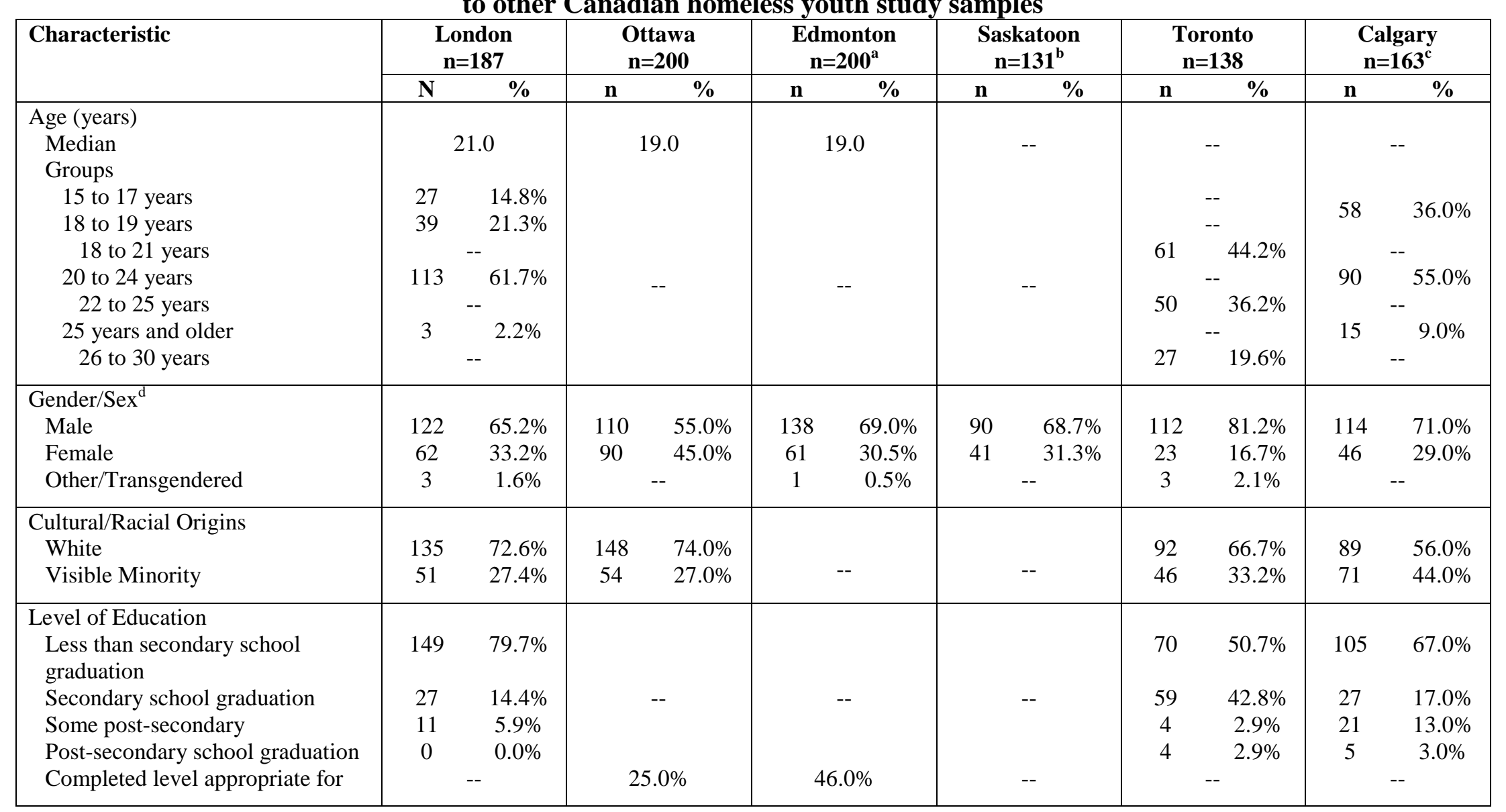

-- Not reported

${ }^{\text {a }}$ Figures represent 2010 cycle

${ }^{\mathrm{b}}$ Figures represent 2009 cycle

c Figures represent youth 'currently on the street'

${ }^{\mathrm{d}}$ London, Edmonton, and Toronto examined Gender while Ottawa, Saskatoon, and Calgary examined Sex 


\section{Apples to Apples}

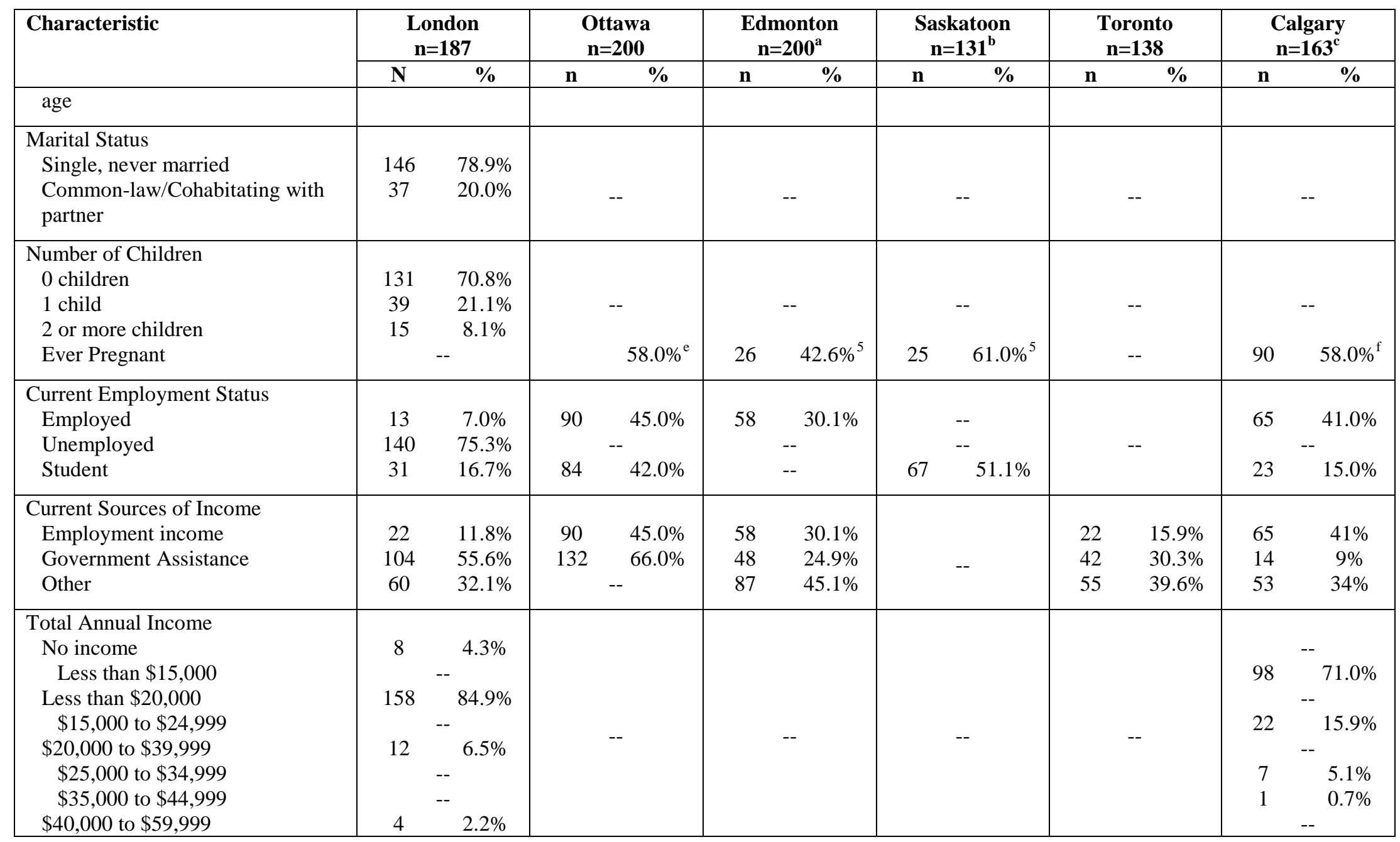

\section{-- Not reported}

${ }^{\mathrm{e}}$ Representative of females only

${ }^{\mathrm{f}}$ Represents pregnancies of self or partner 
Buccieri et al.

\section{Discussion}

Having a sound understanding of population-specific demographics is imperative for creating and implementing informed responses. In this paper the homeless youth sample from YML was compared to a sample of housed Ontario youth, as well as samples of homeless youth in five other Canadian cities. Key demographic factors that were examined included: age, sex, ethnicity, marital status, number of children, education level, employment, and annual income. The results indicated many differences between the youth in London and the housed youth, and mixed results when compared to other homeless youth across the country.

Comparatively, the homeless samples were more highly comprised of older youth, males, and white individuals than the housed sample. Marital status, while only reported upon by the London study, was an important variable that showed a large percentage of homeless youth cohabitating with partners, and more so than their housed peers. These findings suggest the need for further research on cohabitation / marital status among homeless youth, and the need for researchers to include these variables in their demographic data collection.

The findings in relation to number of pregnancies and children indicated that the homeless youth samples reported considerably higher numbers than did housed youth. It is difficult to make direct comparisons with this data, however, given that it was collected and reported in different ways. For instance, some researchers recorded data on pregnancies while others asked about the number of children one has, and some reported data from only female participants. These notable differences mean that direct comparisons cannot be made between the youth samples. However, the key underlying finding of the reported data 
is that homeless youth experience more pregnancies and have more children when compared to their housed peers. This finding is significant and highlights the need for parenting resources and supports among this population of young people.

Educational attainment was found to be higher among the housed youth than those who are homeless, with the gap growing as age increases. This suggests there is an urgent need to connect younger homeless youth with education supports before they fall too far behind their housed peers. Although low educational attainment was found in all homeless samples, the results, like the parenting data, were difficult to compare directly as a result of inconsistent collection and reporting methods. Whereas Ottawa and Edmonton reported on whether the youth completed age appropriate levels of education, cities like London, Toronto, and Calgary reported education as a categorical variable. The data from each available city indicates low educational attainment, and attainment lower than housed youth, but direct comparisons are not able to be made given the key data differences.

Finally, while methodological differences in the collection of employment and income data present comparative challenges, the results suggest that homeless youth are far more likely to be unemployed and to receive social assistance than the housed Ontario youth. Within the homeless youth samples, the data was sparse but generally showed that incomes sources other than employment were common in all cities but Calgary.

\section{Limitations}

This study was subject to several limitations. The first limitation is that the analysis conducted here was a secondary analysis of data previously collected. It is therefore limited to the measures that had already been collected, and the purpose for which they had been 
Buccieri et al.

collected. Secondly, all of the responses given by participants were, in part, based on their ability to remember previous events. As such, the data could be affected by a certain amount of recall bias. Third, the participants included in the YML sample all were experiencing serious self-reported mental health disorders, which may have contributed to differences in the demographic profiles. Finally, because of the different instruments used in each sample, some of the comparisons made between the London homeless youth sample and other youth samples could not be exact. Thus, these comparisons should be made with caution.

\section{Conclusion}

Overall, this study highlights three important outcomes. First, demographic data is not consistently collected and/or reported upon by researchers, which makes comparative analysis difficult. Moving toward a standardization of demographic data among youth researchers would improve the quality of the data and allow for a better understanding of sample representation. Second, comparisons between homeless and housed youth indicated that the homeless youth were significantly different in many important ways. More research is needed to better understand the social and structural factors that contributed to lower educational attainment, higher pregnancy/parenting rates, increased cohabitation, greater unemployment, and low annual incomes among youth who are homeless. Finally, the demographic comparison between the six homeless youth samples indicated some similarities and some key differences, particularly in relation to data on pregnancies / parenting, education, employment, and income. Where possible, researchers, policy- 
Apples to Apples

makers, and service providers should collaborate to share resources, best practices, and strategies across these (and other) cities.

More research is needed to better understand these differences and the contributing factors that affect homeless youth in different cities. Homeless youth in Canada are a diverse population who differ not only from housed youth, but from one another.

Demographic analysis is needed to better understand these young people and to implement targeted and informed responses. 
Buccieri et al.

\section{References}

Abramovich, I. A. (2012). No safe place to go: LGBTQ youth homelessness in Canada: Reviewing the literature. Canadian Journal of Family and Youth, 4(1), 29-51.

Alberta Health Services. (2011). Enhanced street youth surveillance: Edmonton site results 1999-2010. Alberta: Alberta Health Services.

American Psychological Association. (2001). Publication manual of the American psychological association ( $5^{\text {th }}$ ed.). Washington: American Psychological Association.

Baker Collins, S. (2013). Childhood stress and mobility among rural homeless youth. In S. Gaetz, B. O’Grady, K. Buccieri, J. Karabanow, \& A. Marsolais (Eds.), Youth homelessness in Canada: Implications for policy and practice (53-74). Toronto: Canadian Homelessness Research Network.

Baron, S. W. (1999). Street youths and substance use: The role of background, street lifestyle, and economic factors. Youth \& Society, 31(1), 3-26.

Boivin, J. F., Roy, E., Haley, N., \& Galbaud du Fort, G. (2005). The health of street youth: A Canadian perspective. Canadian Journal of Public Health, 96(6), 432-437.

Chisolm, D. J., Mulatu, M. S., \& Brown, J. R. (2009). Racial/ethnic disparities in the patterns of co-occurring mental health problems in adolescents in substance abuse treatment. Journal of Substance Abuse Treatment, 37(2), 203-210.

Coates, J., \& McKenzie-Mohr, S. (2010). Out of the frying pan, into the fire: Trauma in the lives of homeless youth prior to and during homelessness. Journal of Sociology and Social Welfare, 37(4), 65-96.

DeMatteo, D., Major, C., Block, B., Coates, R., Fearon, M., Goldberg, E., ... Read, S. E. (1999). Toronto street youth and HIV/AIDS: Prevalence, demographics, and risks. Journal of Adolescent Health, 25(5), 358-366.

Frederick, T. J., Ross, L. E., Bruno, T. L., \& Erickson, P. G. (2011). Exploring gender and sexual minority status among street-involved youth. Vulnerable Children and Youth Studies, 6(2), 166-183.

Gaetz, S. (2004). Safe streets for whom? Homeless youth, social exclusion, and criminal victimization. Canadian Journal of Criminology and Criminal Justice, 46(4), 423455.

Gaetz, S., O’Grady, B., \& Buccieri, K. (2010). Surviving crime and violence: Street youth and victimization in Toronto. Toronto: Justice for Children and Youth and the Homeless Hub. 
Gangamma, R., Slesnick, N., Toviessi, P., \& Serovich, J. (2008). Comparison of HIV risks among gay, lesbian, bisexual, and heterosexual homeless youth. Journal of Youth and Adolescence, 37(4), 456-464.

Gattis, M. N. (2013). An ecological systems comparison between homeless sexual minority youths and homeless heterosexual youths. Journal of Social Service Research, 39(1), 38-49.

Haber, M. G., \& Toro, P. A. (2009). Parent-adolescent violence and later behavioral health problems among homeless and housed youth. American Journal of Orthopsychiatry, 79(3), 305-318.

Kelly, K., \& Caputo, T. (2007). Health and street/homeless youth. Journal of Health Psychology, 12(5), 726-736.

Kirst, M., \& Erickson, P. (2013). Substance use and mental health problems among streetinvolved youth: The need for a harm reduction approach. In S. Gaetz, B. O'Grady, K. Buccieri, J. Karabanow, \& A. Marsolais (Eds.), Youth homelessness in Canada: Implications for policy and practice (185-198). Toronto: Canadian Homelessness Research Network.

Leslie, M. B., Stein, J. A., \& Rotheram-Borus, M. J. (2002). Sex-specific predictors of suicidality among runaway youth. Journal of Clinical Child and Adolescent Psychology, 31(1), 27-40.

Linton, A. B., Singh, M. D., Turbow, D., \& Legg, T. J. (2009). Street youth in Toronto, Canada: An investigation of demographic predictors of HIV status among street youth who access preventive health and social services. Journal of HIV / AIDS \& Social Services, 8(4), 375-396.

Marshall, B. D., Kerr, T., Livingstone, C., Li, K., Montaner, J. S. G., \& Wood, E. (2008). High prevalence of HIV infection among homeless and street-involved Aboriginal youth in a Canadian setting. Harm Reduction Journal, 5(1), 35.

Marshall, B. D., Shannon, K., Kerr, T., Zhang, R., \& Wood, E. (2010). Survival sex work and increased HIV risk among sexual minority street-involved youth. Journal of Acquired Immune Deficiency Syndrome, 53(5), 661-664.

McCaskill, P. A., Toro, P. A., \& Wolfe, S. M. (1998). Homeless and matched housed adolescents: A comparative study of psychopathology. Journal of Clinical Child Psychology, 27(3), 306-319.

Mental Health Commission of Canada. (2008). MHCC research demonstration projects in mental health and homelessness. Canada: Mental Health Commission of Canada. 
Buccieri et al.

Nichols, N. (2013). Nobody “signs out of care." Exploring institutional links between child protection services and homelessness. In S. Gaetz, B. O'Grady, K. Buccieri, J. Karabanow, \& A. Marsolais (Eds.), Youth homelessness in Canada: Implications for policy and practice (75-93). Toronto: Canadian Homelessness Research Network.

Noell, J. W., \& Ochs, L. M. (2001). Relationship of sexual orientation to substance use, suicidal ideation, suicide attempts, and other factors in a population of homeless adolescents. Journal of Adolescent Health, 29(1), 31-36.

O'Grady, B., \& Gaetz, S. (2004). Homelessness, gender and subsistence: The case of Toronto street youth. Journal of Youth Studies 7(4), 397-416.

O’Grady, B., Gaetz, S., \& Buccieri, K. (2011). Can I see your ID? The Policing of Youth Homelessness in Toronto. Toronto: Justice for Children and Youth and the Homeless Hub.

Ottawa Public Health. (2011). Enhanced street youth surveillance in Ottawa 2011. Ottawa: Ottawa Public Health.

Public Health Agency of Canada. (2008). Filling the gaps in our knowledge of youth health: Enhanced surveillance of Canadian street youth (E-SYS). Ottawa: Public Health Agency of Canada.

Public Health Services. (2011). E-SYS fact sheets. Saskatoon: Public Health Services.

Ray, N. (2006). Lesbian, gay, bisexual and transgender youth: An epidemic of homelessness. New York: National Gay and Lesbian Task Force Policy, Institute and the National Coalition for the Homeless.

Rew, L., Whittaker, T. A., Seehafer, M. A., \& Smith, L. R. (2005). Sexual health risks and protective resources in gay, lesbian, bisexual, and heterosexual homeless youth. Journal for Specialists in Pediatric Nursing 10(1), 11-19.

Rohde, P., Noell, J., Ochs, L., \& Seeley, J. R. (2001). Depression, suicidal ideation and STD-related risk in homeless older adolescents. Journal of Adolescence 24(4), 447460.

Ruttan, L, LaBoucane-Benson, P., \& Munro, B. (2008). “A story I never heard before": Aboriginal young women, homelessness, and restoring connections. Pimatisiwin: A Journal of Aboriginal \& Indigenous Community Health, 6(3), 31-54.

Ruttan, L., LaBoucane-Benson, P., \& Munro, B. (2010). "Home and native land": Aboriginal young women and homelessness in the city. First Peoples Child \& Family Review, 5(1), 67-77. 
Salomonsen-Sautel, S., Van Leeuwen, J. M., Gilroy, C., Boyle, S., Malberg, D., \& Hopfer, C. (2008). Correlates of substance use among homeless youths in eight cities. The American Journal on Addictions, 17(3), 224-234.

Sanders, B., Lankenau, S. E., Jackson-Bloom, J., \& Hathazi, D. (2008). Multiple drug use and polydrug use amongst homeless traveling youth. Journal of Ethnicity in Substance Abuse, 7(1), 23-40.

Shillington, A. M., Bousman, C. A., \& Clapp, J. D. (2011). Characteristics of homeless youth attending two different youth drop-in centers. Youth \& Society, 43(1), 28-43.

Thompson, S. J., Bender, K., Windsor, L., Cook, M. S., \& Williams, T. (2010). Homeless youth: Characteristics, contributing factors, and service options. Journal of Human Behavior in the Social Environment, 20(2), 193-217.

Toro, P. A., Lesperance, T. M., \& Braciszewski, J. M. (2011). The heterogeneity of homeless youth in America: Examining typologies. USA: Homeless Research Institute.

Tyler, K. A., \& Beal, M. R. (2010). The high-risk environment of homeless young adults: Consequences for physical and sexual victimization. Violence and Victims, 25(1), 101-115.

Tyler, K. A., Whitbeck, L. B., Hoyt, D. R., \& Cauce, A. M. (2004). Risk factors for sexual victimization among male and female homeless and runaway youth. Journal of Interpersonal Violence, 19(5), 503-520.

Votta, E., \& Manion, I. (2004). Suicide, high-risk behaviors, and coping style in homeless adolescent males' adjustment. Journal of Adolescent Health, 34(3), 237-243.

Walls, N. E., Hancock, P., \& Wisneski, H. (2007). Differentiating the social service needs of homeless sexual minority youths from those of non-homeless sexual minority youths. Journal of Children and Poverty, 13(2), 177-205.

Wolfe, S. M., Toro, P. A., \& McCaskill, P. A. (1999). A comparison of homeless and matched housed adolescents on family environment variables. Journal of Research on Adolescence, 9(1), 53-66.

Worthington, C., MacLaurin, B., Huffey, N., Dittmann, D., Kitt, O., Patten, S., \& Leech, J. (2008). Calgary youth, health and the street: Final report. Calgary: University of Calgary. 